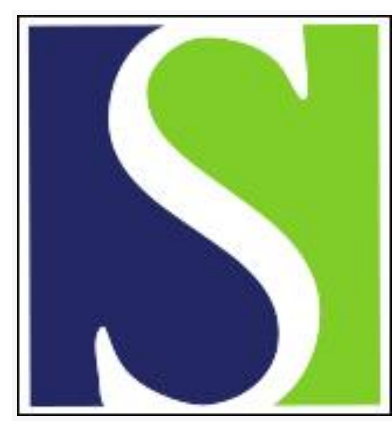

Scand J Work Environ Health 2008;34(2):107-112

https://doi.org/10.5271/sjweh.1221

Published online: 12 May 2008, Issue date: 31 Apr 2008

What makes men and women with musculoskeletal complaints decide they are too sick to work?

by Hooftman WE, Westerman MJ, van $\operatorname{der}$ Beek AJ, Bongers PM, van Mechelen W

Affiliation: Department of Public and Occupational Health, EMGO Institute, VU University Medical Center, Amsterdam, Netherlands.

The following article refers to this text: 2009;35(2):85-95

Key terms: absenteeism; back; gender; man; musculoskeletal complaint; neck; qualitative research; sickness; sickness absence; upper extremity; woman; work

This article in PubMed: www.ncbi.nlm.nih.gov/pubmed/18470439

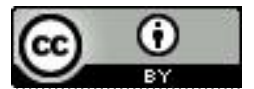




\title{
What makes men and women with musculoskeletal complaints decide they are too sick to work?
}

\author{
by Wendela E Hooftman, PhD, ${ }^{1,2}$ Marjan J Westerman, PhD, ${ }^{1}$ Allard J van der Beek, PhD,, 2 Paulien M \\ Bongers, PhD, ${ }^{2,3}$ Willem van Mechelen, $P h D^{1,2}$
}

\begin{abstract}
Hooftman WE, Westerman MJ, van der Beek AJ, Bongers PM, van Mechelen W. What makes men and women with musculoskeletal complaints decide they are too sick to work? Scand J Work Environ Health. 2008;34(2):107-112.
\end{abstract}

\begin{abstract}
Objective The objective of this study was to determine what makes men and women with musculoskeletal complaints decide to call in sick for work.

Methods Qualitative, face-to-face interviews were used with employees (16 men and 14 women) who had called in sick due to a musculoskeletal complaint and who expected to be absent from work for at least 2 weeks on sick leave.

Results The participants fell into the following two main groups: those who were off sick because of a diagnosed medical condition, such as a fracture, and those who were off sick because of an unidentifiable complaint, such as low-back pain. Employees in the former group called in sick because they were in the hospital or because they reckoned that their condition was too serious to warrant a continuation of work. Employees in the latter group felt hesitant and insecure and found it hard to judge whether absenteeism was justified. They decided either to "play it safe" and stay off work to prevent the complaints from worsening or to seek advice from medical professionals. Their advice did not include explicit instructions to stay at home, but were usually interpreted as such. Finally, women, but not men, were likely to call in sick if they felt that their home situation was being negatively affected by attempts to keep working while suffering physical complaints.

Conclusions The decision to call in sick is not taken lightly. Employees with nonspecific disorders base their decision on several factors, including advice from medical professionals. A factor found only among women was work-home interference.
\end{abstract}

Key terms absenteeism; back; gender; neck; qualitative research; upper extremity.

The high prevalence of sick leave is generally recognized as a major problem in modern society. However, different groups of employees may display distinct differences in the patterns of sick leave; for example, younger employees tend to be off sick more often than older employees, and women more often than men (1-3). However, results are not always consistent, and a higher degree of sickness absenteeism has also been found for men (4) and older workers (3).

van den Bossche et al (5) showed that $56 \%$ of Dutch female employees and $49 \%$ of male employees had been on sick leave during the previous year. Women had been absent an average of 1.4 times and 8 days, while men had been absent an average of 1.1 times and 8.2 days. However, $8.1 \%$ of the women and $5.9 \%$ of the men had been absent for over 8 weeks. The higher frequency of absence for women, on the average (about) equal with respect to the duration of absenteeism for men and women but with more-frequent long absenteeism among women, corresponds with the results of earlier studies, both in the Netherlands (6) and in other countries $(2,7)$. However, data on gender differences in the average duration of absenteeism are ambiguous $(2,7)$. Recent Scandinavian studies have shown that the frequency of sickness "presenteeism" (ie, working when sick leave should be taken) was also greater among women $(8,9)$. This finding suggests that the pattern of absenteeism (eg, frequent short-term leave versus infrequent long-term leave) differs between the genders. This phenomenon may be caused by differences in the reasons for calling in sick.

1 Department of Public and Occupational Health, EMGO Institute, VU University Medical Center, Amsterdam, Netherlands.

2 Body@Work, Research Centre Physical Activity, Work and Health, TNO VUmc, Amsterdam, Netherlands.

3 TNO Quality of Life, Work and Employment, Hoofddorp, Netherlands.

Correspondence to: Dr Allard van der Beek, EMGO Institute, Van der Boechorststraat 7-9, NL-1081 BT Amsterdam, Netherlands. [E-mail: a.vanderbeek@vumc.nl] 
The decision to call in sick is an action that is taken within a certain cultural and social framework. It is therefore important to have some insight into the process of sicklisting within a country. In the Netherlands, during the first 2 years of absenteeism, employers are obliged to pay a sick worker at least $70 \%$ of their regular pay. However, in most collective labor agreements it has been agreed that during the first year of absenteeism the actual pay is $100 \%$. Furthermore, in contrast to workers in many other countries, Dutch workers do not have to provide a sickness certificate to be able to call in sick for work. Therefore, calling in sick for work is predominantly their own decision.

Although absenteeism is legally justified only when a person is unable to perform his or her usual tasks because of a health problem, such a situation might not always be the case. Previous research (10-14) has shown that factors that do not specifically have to do with task performance are also important. These factors range from practical issues, such as getting paid or finding a replacement, and work-related issues, such as job satisfaction, commitment, job security, job demands, decision latitude, workhours, and the like, up to the extent to which a person "wants" to be off work. For example, Donders et al (15) showed that, when work interferes with an employee's personal life (work-family

Table 1. General data on the participants.

\begin{tabular}{|c|c|c|c|c|c|c|}
\hline \multirow[t]{2}{*}{ Characteristic } & \multicolumn{3}{|c|}{ Men $(\mathrm{N}=16)$} & \multicolumn{3}{|c|}{ Women $(\mathrm{N}=14)$} \\
\hline & N & Mean & Range & $\mathrm{N}$ & Mean & Range \\
\hline Age (years) & . & 34.1 & $22.4-50.8$ & $\cdot$ & 41.0 & $21.0-52.9$ \\
\hline \multicolumn{7}{|l|}{ Educational level } \\
\hline None or lower secondary & 6 & . & . & 4 & . & . \\
\hline Intermediate secondary & 6 & . & . & 8 & $\cdot$ & $\cdot$ \\
\hline $\begin{array}{l}\text { Higher secondary or } \\
\text { university }\end{array}$ & 3 & $\cdot$ & $\cdot$ & 2 & $\cdot$ & $\cdot$ \\
\hline Unknown & 1 & . & $\cdot$ & 0 & $\cdot$ & $\cdot$ \\
\hline Workhours per week & $\cdot$ & 42.1 & $36-60$ & $\cdot$ & 25.6 & $11-40$ \\
\hline Years working with employer & $\cdot$ & 6.6 & $1-23$ & . & 8.9 & $0.8-21$ \\
\hline \multicolumn{7}{|l|}{ Complaint region } \\
\hline Shoulder or neck & 8 & . & . & 3 & . & . \\
\hline Hand or arm & 1 & . & . & 0 & . & . \\
\hline Back & 2 & . & . & 10 & . & . \\
\hline Leg or foot & 4 & . & . & 1 & . & . \\
\hline Several regions & 1 & . & . & - & . & . \\
\hline \multicolumn{7}{|l|}{ Nature of complaint } \\
\hline Specific disorders & 7 & . & . & - & . & . \\
\hline Nonspecific disorders & 9 & . & . & 14 & - & . \\
\hline \multicolumn{7}{|c|}{ Duration of complaint prior to absenteeism } \\
\hline 0 days & 5 & . & . & 4 & . & . \\
\hline$<1$ week & 0 & . & . & 1 & . & . \\
\hline 1 week-6 months & 3 & . & . & 6 & . & . \\
\hline $6-12$ months & 2 & . & . & 2 & . & . \\
\hline$>12$ months & 6 & · & . & 1 & . & $\cdot$ \\
\hline \multicolumn{7}{|l|}{ Previous absenteeism } \\
\hline Yes & 3 & . & . & 3 & . & . \\
\hline No & 13 & . & . & 11 & . & . \\
\hline
\end{tabular}

interference), the interference influenced the sick leave patterns of both men and women, but when personal life interfered with work (family-work interference), the interference had no effect on sick leave. However, whereas women attach more importance to private circumstances (child care, domestic help) when taking sick leave, men pay more attention to work-related factors (taking work home, support from superiors). Although it is known that these factors influence the decision to call in sick, it is not clear how they operate. The aim of this study was therefore to explore how men and women with musculoskeletal complaints decide to call in sick for work. By doing so, this study adds insight into the process of calling in sick and can provide some clues about how sickness absenteeism can be prevented.

\section{Study population and methods}

The participants were recruited through two branches of an occupational health service in the Netherlands. As a part of the standard procedure, all of the employees received a telephone call from the occupational health service to confirm their absenteeism 2 days after they called in sick. They were asked why they had called in sick and how long they expected to be absent from work. Those who said that they suffered from a musculoskeletal complaint and that they would probably be absent for at least 2 weeks were asked to participate in the study. Altogether 49 agreed to have information about the aim and method of the study sent to their home address. The number who refused was not registered. However, according to the occupational health service, refusals were few. Two days after the information had been sent the workers were contacted by phone to ensure that they had read and understood the information, and they were then were asked whether they wanted to participate. Most of these 49 persons (16 men and 14 women) agreed to be interviewed and completed the informed consent form. [See table 1 for data on the participants.] The workers who did not agree to participate were either not interested in the study or could not be reached by telephone.

The participants were interviewed at their home, except for one, who, upon request, was interviewed in a workplace conference room. They were interviewed alone, except for three cases, when another person was present [spouse $(\mathrm{N}=1)$, young children $(\mathrm{N}=1)$, son, a translator $(\mathrm{N}=1)]$. The interviews were open-ended and conducted with an interview guide. They lasted 45-90 minutes and were geared to allow the participants to speak freely about their reasons for being off sick. Each interview opened with the question "Why did you call in sick for work?" Possible follow-up questions or prompts were "Were there additional factors that 
caused you to call in sick?", "Describe your work at the time you called in sick", and "Describe your personal life at the time you called in sick." After the interview, the participants completed a short questionnaire on sociodemographics. During the interviews, extensive research notes were taken, the interviews were recorded, and a verbatim transcript was made. Unfortunately, in two interviews, the quality of the tape was too poor for a transcript to be made. However, since research notes were taken and the same researcher both interviewed the participants and participated in the analyses, the data from these interviews were not completely lost.

Unlike in quantitative research, in qualitative research, data gathering and data analysis are not separate processes, and there is risk of influence by the researchers' personal opinions. It is therefore highly important to analyze the data systematically, be aware of one's preminitions, and constantly seek for both confirmatory and contradictory results (16). In this study, the analyses were conducted by the interviewer (WH) in close collaboration with a second researcher (MW), who was not directly involved in the interviewing and therefore was better able to pick up on personal opinions. For the analyses, the constant comparison method was used, in which each item was checked or compared with the rest of the data to establish analytical categories (17). In order to carry out this process, we divided the interviews into three subsets. First, according to our impressions, gained during the interviews, the 10 most informative interviews were selected. The interviews were then opencoded by the first author to identify relevant themes. The interviews were read and reread several times to ensure that all the themes were identified. Similar themes were grouped into categories, and preliminary conclusions were discussed with a second member of the research team (MW). The remaining interviews were divided into a second and third set. The second set of interviews was read, during which conscious efforts were made to detect further examples of the identified themes and, if applicable, to identify new themes. Special attention was paid to revealing any contradictions to the identified themes. After analyzing the second set of interviews, we updated the themes and conclusions and again discussed the results with the second team member. The third set of interviews was then used to either confirm or question the results. This final set of interviews also included the interviews for which it was impossible to make a verbatim description. Since this set provided no further insight, it was concluded that saturation had been reached.

\section{Results}

Two groups of employees emerged, each with a different decision-making process, those who were off sick because of a diagnosed medical condition, such as a fracture (specific disorders), and those who were off sick because of an unidentifiable complaint (nonspecific disorders) (eg, low-back pain).

\section{Specific disorders}

For the participants with specific disorders, the decision to call in sick was easily made, and it was based on only a few factors. They were absent from work either because they were in the hospital or because they rated their disorder as too serious to continue work. The latter was sometimes influenced by advice from medical professionals or by previous experience with the consequences of surgery. [See example 1, which shows reasons for calling in sick with specific disorders.]

\section{Nonspecific disorders}

Insecurity. The employees with nonspecific disorders wrestled with the decision to call in sick. The fact that their complaints were often not visible to others and that no diagnosis had been given made them feel insecure. [See example 2, which shows the role of insecurity when workers call in sick with nonspecific disorders.] These participants indicated that the main reason for their absenteeism was the imbalance between (physical) work demands and reduced physical capacity. However, they found it difficult to judge their symptoms. Considerations ranged from whether they were serious enough to call in sick, up to whether they might get worse if they continued to work. In addition, they were afraid that friends, family, and neighbors would see them as

\section{Example 1. Reasons for calling in sick with specific disorders.}

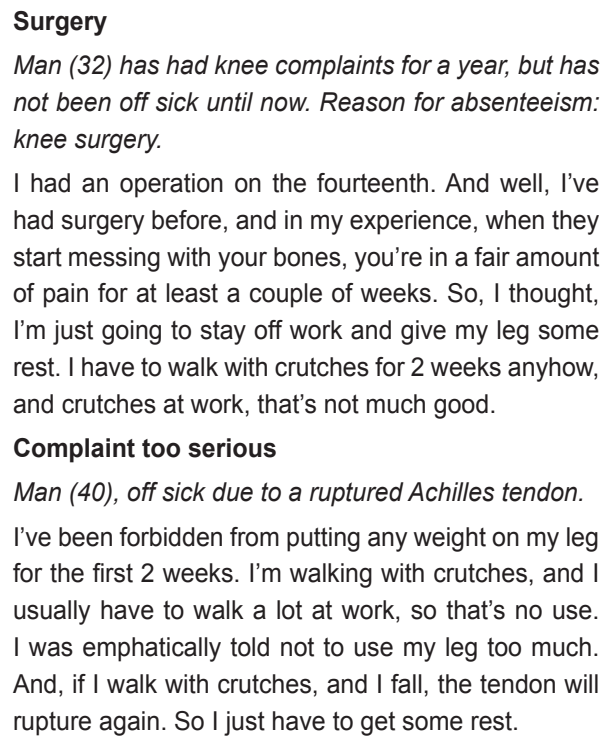




\section{Example 2. Role of insecurity in the reasons} for calling in sick.

\section{Judging complaints}

Woman (49), complaints for 9 months. Has continued working until now. Considers herself incapable of judging whether she should call in sick. Feels this situation has aggravated her complaints.

When you have the flu, you stay at home. But symptoms that can't be seen on the outside, that's when I find it hard to take a decision. Maybe I should have acted sooner. I find it difficult, making that decision.

\section{Views from others}

Woman (41) has had back complaints for 9 months. You don't need to stay in bed all day, you have to keep moving. And then you run into someone from work, and you think, maybe they think "Well, she's able to do that". It's just an idea you get, you know what I mean. After all, people talk.

Man (22) has had shoulder complaints for 6 months and has been off work with the same complaints before.

When I want to go out, I just go, but, well, then people say you can go to work as well. When I go out I wear a sling, purely to show the outside world: "He's got something that is wrong with his shoulder, so watch out."

"slackers" if they were off work but were still able to walk around without visible discomfort. The following two strategies for coping with insecurity emerged: (i) play it safe and (ii) seek advice. [See example 3, which shows strategies used when workers call in sick for nonspecific disorders.] The first strategy was usually chosen because there was no diagnosis or prognosis for the complaints; it was believed that staying off work would prevent the complaints from worsening. The reason for choosing this strategy was that the sufferer had worked with the same symptoms in the past, and the symptoms had not diminished.

Employees who adopted the second strategy believed that they did not have enough expertise to decide whether they needed to stay off work. They therefore (un)consciously sought advice from medical professionals such as their general practitioner or physiotherapist. The aim was twofold, to help them decide on the seriousness of the complaint in relation to their work and to legitimize their absenteeism to their employer and their friends. According to the participants, medical professionals hardly ever instructed them explicitly to call in sick, but advised them to rest or to avoid overexerting their arm (or leg or back). Such advice was regarded as highly significant because it came from experts. The employees concluded that, in order to obey to these experts, they needed to call in sick. Advice from other sources, such as friends and family, was rarely sought.

\section{Example 3. Strategies used by workers with nonspecific complaints.}

\section{Play it safe}

Man (29) has had wrist complaints for 2 years. Hasn't called in sick before.

I'm trying hard to fight it. It takes so much energy, I just can't handle it anymore. The last time I thought "just keep going", but this time, I felt I shouldn't be doing that anymore. This time, I first want to make sure it gets a bit better, and get some straight answers. I want to know what the problem is, if anything's been damaged, if I can keep working like this. I first want to find out what it is and how serious it is.

\section{Seeking advice}

Woman (49), has had complaints for 9 months. Has continued working until now. Considers herself incapable of judging whether to call in sick. Feels this situation has aggravated her complaints

Six weeks ago my physiotherapist asked how are things at work? I told him not good. Well, he said, then you'll have to stay home for a while and see whether it gets a bit better instead of worse. And that's what I told them at work. At least I could then tell my boss that my physiotherapist doesn't understand why l'm still working.

Man (44) has had neck complaints for 10 months. Has always continued working.

I've called in sick now because my physiotherapist gave me an ear-bashing. Are you still working? Nobody told me to call in sick. They just told me not to use my arm too much. Well, I reckon that, if I can't use my arm, I have to stay at home.

Spontaneous advice was appreciated because it showed general interest, but was not pursued. The rationale was that this advice was given by people who were incompetent and should therefore stay out of it. Advice from friends and family was therefore usually ignored, while advice from medical experts directly influenced and legitimized the absenteeism, even if it did not include explicit instructions to stay off work.

Private life. Private life was another issue that was important when the participants decided to call in sick for work. However, this finding was only true for the women. The women with small children reported that they were more likely to call in sick if the combination of work and symptoms was having a negative effect on their private life. [See example 4, which shows the role of private life when workers call in sick for nonpsecific disorders.] They did not mind working while suffering pain or discomfort, but, if it proved so draining that they had no energy left for their domestic tasks, they found it self-evident that they needed to change the situation. They felt that, at work, someone else could, and would, fill in for them, while at home they were ultimately 
responsible and could not be missed. Consequently, these women decided to call in sick for work.

\section{Discussion}

The aim of our study was to qualitatively explore how men and women decide to call in sick for work. The results indicate that the decision to call in sick for work is not taken lightly by either men or women and that employees with nonspecific disorders base their decision on several factors. Work-home interference was found to be an issue for the women, but not for the men.

Before we go deeper into these results, the strengths and limitations of the study should be discussed. The strength of the study was its explorative, qualitative design, which can provide deeper insight into the process of calling in sick than a quantitative study can do. A limitation of the study was that, due to the qualitative design, a limited number of interviews was performed, which limits the external validity of the results. However, unlike quantitative research, the aim of qualitative research is not to find results that are widely applicable, but to go in-depth and to show underlying mechanisms.

Another limitation of our study was that the men and women interviewed were absent due to different conditions. The men were more often absent due to neck or shoulder complaints, while the women were often absent due to back problems. Furthermore, almost half of the men were absent due to specific complaints, but none of the women complied with this criterion. We did not find a difference in the decision-making process between complaint regions, but we did find a difference between specific and nonspecific disorders. Since this difference also implies a male-female division, the result that workers with specific symptoms easily make the decision to be absent from work may also indicate that men more easily make the decision to be absent from work. Additional research is needed to determine whether this in fact may be a gender difference. Finally, the extent to which the results of our study can be generalized remains unknown, since the Netherlands has an exceptional social security system when compared with the systems of most other countries.

The one factor that, in our study, was found for the women alone was work-home interference. Having a double workload is usually mentioned in association with a higher prevalence of complaints among the women (18-22). Work-family interference has also been shown to affect sick leave (through perceived health) (15). Our results indicate that work-home interference is indeed a factor in absenteeism, but only for women, and that this association is influenced by the responsibility women feel towards their homes.

\section{Example 4. Role of private life in the reasons for calling in sick.}

Woman (41) has had back complaints for 9 months. Feels that working with back complaints is causing so many problems that it is hard to do anything at home.

Calling in sick is difficult enough. Will I or won't I? I always just kept going until the work caused so much discomfort that I had no energy left when I came home. That's when you start thinking "What am I doing?" I have a family at home that needs taking care of, and I feel it's important to be there for them. I don't want to be incapable of doing anything at home just because I want to keep working. That's not what it's about.

Earlier studies (10-14) have shown many factors that influence absenteeism, such as payment, replacement, and motivational issues. In our study, none of these issues seemed to be important when a participant decided to call in sick for work. However, our results do corroborate those of Hansson et al (23), who found that, for persons with new (diagnosed) spinal-related pain, all that mattered when they decided to call in sick for work was the disorder. The people with long-term (undiagnosed) spinal-related pain tried to strike a balance between the factors that prompted them to keep working and those that prompted them to call in sick. Their strategy was to call in sick in order to get a diagnosis, readjust the work arrangements, and to recover from their complaints. This approach closely resembles our "play it safe" strategy. Our "advice-seeking" strategy was not found by Hansson et al (23); this lack of agreement may be due to differences in the social security systems, since, in Sweden, a sick leave of 2 weeks needs to be decided by a physician, not the employee. Insecurity about whether absenteeism was justified made workers with nonspecific disorders seek advice from medical professionals. This advice seldom answered the dilemma of whether or not to call in sick. However, the general advice to rest was interpreted as instructions to stay at home. Hussey et al (24) found that general practitioners experience a similar quandary when deciding whether to issue a physician's certificate if the patient has no objective clinical diagnosis. In the Netherlands employees do not need a physician's certificate to stay off work; therefore, general practitioners are not forced to make a decision on the matter. This situation may allow them to evade the issue altogether and to offer nonspecific advice. The incidence of potentially work-related ailments is, however, high, and musculoskeletal complaints are the primary reason for work-related visits to a general practitioner (25). Hence the influence of the general practitioner on absenteeism may be fairly high. This situation suggests that general practitioners may need 
more training on work-related matters in order to be able to give appropriate advice. At the same time, however, general practitioners should be aware that nonspecific advice is not interpreted as such and that they do directly influence sick leave. Their advice should, therefore, be more explicit. When a general practitioner means, "rest, but keep working" he should say so.

In conclusion, the decision to call in sick is not taken lightly. Employees with nonspecific disorders base their decision on several factors, including advice from medical professionals. To prevent unnecessary sick leave, general practitioners and physiotherapists should explicitly give advice on whether or not to call in sick. Women are more likely to call in sick if they feel that working with complaints has too many consequences for their home situation. Some of this sick leave might be prevented by giving women better options to improve their perceived work-home balance.

\section{References}

1. Gluck JV, Oleinick A. Claim rates of compensable back injuries by age, gender, occupation, and industry: do they relate to return-to-work experience? Spine. 1998;23(14):1572-87.

2. Sharp C, Watt S. A study of absence rates in male and female employees working in occupations of equal status. Occup Med. 1995;45(3):131-6.

3. Barmby TA, Ercolani MG, Treble JG. Sickness absence: an international comparison. Econ J. 2002;112(480):F315-F331.

4. Gimeno D, Benavides FG, Benach J, Amick BC 3rd. Distribution of sickness absence in the European Union countries. Occup Environ Med. 2004;61(10):867-9.

5. van den Bossche SNJ, Hupkens CLH, Ree SJM de, Smulders PGW. Nationale Enquête Arbeidsomstandigheden 2005: methodologie en globale resultaten. [Netherlands Working Conditions Survey 2005: methodology and overall results]. Hoofddorp (Netherlands): TNO Work \& Employment; 2006.

6. Cuelenare B, Jetten B, van Kooten D. Verschillen in ziekteverzuim tussen mannen en vrouwen?: verklaringen onderzocht. [Differences in sickness absenteeism between men and women: explanations examined]. Tijdschr Arb. 1996;12(1):43-55.

7. Hensing G, Brage S, Nygard JF, Sandanger I, Tellnes G. Sickness absence with psychiatric disorders-an increased risk for marginalisation among men? Soc Psychiatry Psychiatr Epidemiol. 2000;35(8):335-40.

8. Aronsson G, Gustafsson K. Sickness presenteeism: prevalence, attendance-pressure factors, and an outline of a model for research. J Occup Environ Med. 2005;47(9):958-66.

9. Aronsson G, Gustafsson K, Dallner M. Sick but yet at work: an empirical study of sickness presenteeism. J Epidemiol Com- munity Health. 2000;54(7):502-9.

10. Johansson G, Lundberg I. Adjustment latitude and attendance requirements as determinants of sickness absence or attendance: empirical tests of the illness flexibility model. Soc Sci Med. 2004;58(10):1857-68.

11. Voss M, Floderus B, Diderichsen F. How do job characteristics, family situation, domestic work, and lifestyle factors relate to sickness absence?: a study based on Sweden Post. J Occup Environ Med. 2004;46(11):1134-43.

12. Voss M, Floderus B, Diderichsen F. Physical, psychosocial, and organisational factors relative to sickness absence: a study based on Sweden Post. Occup Environ Med. 2001;58(3):17884.

13. Dew K, Keefe V, Small K. 'Choosing' to work when sick: workplace presenteeism. Soc Sci Med. 2005;60(10):227382.

14. Philipsen H. Afwezigheid wegens ziekte een onderzoek naar oorzaken in ziekteverzuim in 83 middelgrote bedrijven [Absenteeism due to sickness, a study of causes of sickness absenteeism in 83 companies]. Groningen (Netherlands): Wolters-Noordhof; 1969.

15. Donders NCGM. Psychosocial workload, work-family interference and health. Determinants of sick leave in university employees [dissertation]. Nijmegen (Netherlands): Radboud Universiteit; 2005.

16. Mays N, Pope C, Qualitative research in health care: assessing quality in qualitative research. BMJ. 2000;320;50-52.

17. Pope C, Ziebland S, Mays N. Qualitative research in health care: analysing qualitative data. BMJ. 2000;320(7227):114 6.

18. Hall E. Double exposure: the combined impact of the home and work environments on psychosomatic strain in Swedish women and men. Int J Health Serv. 1992;22(2):239-60.

19. Krantz G, Ostergren PO. Double exposure: the combined impact of domestic responsibilities and job strain on common symptoms in employed Swedish women. Eur J Public Health. 2001;11(4):413-9.

20. Strazdins L, Bammer G. Women, work and musculoskeletal health. Soc Sci Med. 2004;58(6):997-1005.

21. Martikainen P. Women's employment, marriage, motherhood and mortality: a test of the multiple role and role accumulation hypotheses. Soc Sci Med. 1995;40(2):199-212.

22. Mastekaasa A. Parenthood, gender and sickness absence. Soc Sci Med. 2000;50:1827-42.

23. Hansson M, Boström C, Harms-Ringdahl K. Sickness absence and sickness attendance-what people with neck or back pain think. Soc Sci Med. 2006;62(9):2183-95.

24. Hussey S, Hoddinott P, Wilson P, Dowell J, Barbour R. Sickness certification system in the United Kingdom: qualitative study of views of general practitioners in Scotland. BMJ. 2004;328(7431):88.

25. Weevers HJ, van der Beek AJ, Anema JR, van der Wal G, van Mechelen W. Work-related disease in general practice: a systematic review. Fam Pract. 2005;22(2):197-204.

Received for publication: 19 June 2007 